\title{
InVEST Model-Based Spatiotemporal Analysis of Water Supply Services in the Zhangcheng District
}

\author{
Run Liu ${ }^{1,2,3}$, Xiang Niu 1,2,3,* Bing Wang ${ }^{1,2,3}$ and Qingfeng Song 1,2,3 \\ 1 Research Institute of Forest Ecology, Environment and Protection, Chinese Academy of Forestry, \\ Beijing 100091, China; liurun6046@163.com (R.L.); wangbing@caf.ac.cn (B.W.); songqingfeng@caf.ac.cn (Q.S.) \\ 2 Key Laboratory of Forest Ecology and Environment, State Forestry and Grassland Administration, \\ Beijing 100091, China \\ 3 Dagangshan National Key Field Observation and Research Station for Forest Ecosystem, Xinyu 338033, China \\ * Correspondence: niuxiang@caf.ac.cn; Tel.: +86-10-6288-9334
}

check for updates

Citation: Liu, R.; Niu, X.; Wang, B.; Song, Q. InVEST Model-Based Spatiotemporal Analysis of Water Supply Services in the Zhangcheng District. Forests 2021, 12, 1082. https://doi.org/10.3390/f12081082

Academic Editor: Manuel

Esteban Lucas-Borja

Received: 30 May 2021

Accepted: 19 July 2021

Published: 13 August 2021

Publisher's Note: MDPI stays neutral with regard to jurisdictional claims in published maps and institutional affiliations.

Copyright: (c) 2021 by the authors. Licensee MDPI, Basel, Switzerland. This article is an open access article distributed under the terms and conditions of the Creative Commons Attribution (CC BY) license (https:// creativecommons.org/licenses/by/ $4.0 /)$.

\begin{abstract}
The Zhangcheng District is critically responsible for protecting water resources, preserving sand sources, and improving the ecological environment in Beijing. Quantitative evaluation and research on the ecosystem water supply services in this area are beneficial for developing conservation planning and establishing ecological compensation mechanisms in water conservation areas. In this paper, based on the land use, meteorological, soil, and field observation data of the research area, the InVEST water yield model is used to estimate the water supply of the ecosystem in the Zhangcheng District. The model quantitatively analyzes the spatiotemporal distribution characteristics of water supply services in the basin and the influence of different topographic factors. The results show that the average supply of ecosystem water in the Zhangcheng District is approximately $45 \mathrm{~mm}$, and there is a degree of spatial heterogeneity. The total water supply in the Zhangcheng District is relatively small. The water resource supply in the southwest is relatively small, the rainfall in mountainous forest areas in the southeast is high, its water supply is higher, and the supply of forest land water is relatively high. The high-value areas are mainly distributed at 1500 to $3500 \mathrm{~m}$ and $15^{\circ} \sim 40^{\circ}$; the water supply on the sunny slope is greater than that on the shady slope. With the increase in altitude and slope, the water supply in the basin tends to increase first and then decrease.
\end{abstract}

Keywords: InVEST model; water supply function; ecosystem services; Zhangcheng District

\section{Introduction}

Forest water conservation has become one of the most crucial issues in forest ecosystems [1]. Moreover, the forest canopy, detritus layer, and soil layer are regularly recognized as the main redistribution areas [2,3] that effectively conserve soil moisture and regulate river flow [4,5]. Water resource supply is important in maintaining regional biodiversity and other key ecosystem functions [6,7], affecting the region's population, socio-economic development, and layout [8]. With global climate change, surface water shortages, and the rapid deterioration of the water environment $[9,10]$, quantitative spatial and visual assessment of the water supply capability of regional ecosystems is one of the most important research topics in hydrology and ecology [11-13].

With the development of remote sensing GIS technology and hydrological models [14], more scholars have tried to quantitatively visualize, accurately analyze, and evaluate the function of regional ecosystems through model simulation methods. Simulation methods include the MIKE System Hydrological European (MIKE SHE) model [15], Temperature Vegetation Dryness Index model (TVDI) [16], Soil and Water Assessment Tool (SWAT) model [17], Soil Conservation Service Curve Number method (SCS-CN) model [18], and Integrate Valuation of Ecosystem Services and Tradeoffs (InVEST) model [19]. The InVEST model quantitatively estimates the water supply of different landscapes based on the water balance principle, considering the spatial differences in soil permeability and topography 
under different land uses [13,20-22]. The parameters and characteristic data requirements of the model are low [23], and it can use empirical parameters and quantify ecosystem service functions in the form of thematic maps [24].

Thus far, the InVEST model has been successfully applied by scholars in the assessment of regional ecosystem services on the north coast of $\mathrm{O}^{\prime}$ ahu Island, Hawaii [25], the San Pedro River basin in Arizona [26], the Beijing mountains [4], the upper reaches of the Han River [27], Sanjiangyuan [28], and other regional ecosystem services. However, due to the large geographical and environmental differences between regions, it is crucial to adjust the model parameters according to each research area's characteristics, especially in large- and medium-scale areas where comprehensive field monitoring data are lacking [29]. Simultaneously, significant spatial and temporal differences in the water supply capacity of different ecosystems are closely related to factors such as precipitation, evaporation, land use/overlay changes, topography, soil permeability, and vegetation transpiration [22]. For example, different vegetation types (or ecosystems) have different effects on hydrological factors [30], such as rainfall interception, seepage, evaporation, the distribution and growth status of vegetation, and topographic factors (such as slope direction and altitude), which indirectly or directly affect the spatial pattern of the water supply [31]. Therefore, this paper analyzes the spatial and temporal differentiation characteristics in different ecosystems and clarifies the relationship between water supply and meteorological factors, topographic factors, and land use. Moreover, to provide an important reference for ecological environment construction and protection in the Zhangcheng District, the key driving factors affecting changes in the water supply are examined.

The cities of Zhangjiakou and Chengde (referred to as the Zhangcheng District) are located in the northern part of Beijing and are key in protecting Beijing's water sources, preserving sand sources, and improving the ecological environment. However, due to special location characteristics and historical reasons, the economic development of the Zhangcheng District is relatively slow, regional ecological poverty is prominent, and ecosystem services such as water supply function in river basins are changing, triggering new ecological and environmental problems. Therefore, it is crucial to quantify the water supply service function and the spatial and temporal distribution characteristics of watershed water supply services in the Zhangcheng District. This will clarify the different characteristics of water supply services in different ecosystems and different topographies to provide quantitative visual evaluation results and a scientific basis for key functional zoning, ecological restoration, and ecological compensation of water supply in river basins.

\section{Research Method and Data Processing}

\subsection{Research Site}

The Zhangcheng District is located in northern Hebei Province $\left(113^{\circ} 50^{\prime} \sim 119^{\circ} 15^{\prime} \mathrm{E}\right.$, $39^{\circ} 30^{\prime} \sim 42^{\circ} 40^{\prime} \mathrm{N}$ ). The topography of this area mainly consists of the dam plateau area, the northern Hebei mountain area, and the low hills in northwest Hebei, with the overall terrain gradually decreasing from northwest to southeast (Figure 1a). It belongs to the temperate continental monsoon climate and is characterized by four distinct seasons. The average temperature, precipitation, and potential evaporation in the upper plateau area of the dam are $-1 \sim 2{ }^{\circ} \mathrm{C}, 300 \sim 400 \mathrm{~mm}$, and $1400 \mathrm{~mm}$, respectively. Due to the influence of topography and latitude, the temperature in the mountains near the dam gradually increases from north to south, and the average temperature and precipitation are $5 \sim 9{ }^{\circ} \mathrm{C}$ and $400 \sim 600 \mathrm{~mm}$, respectively. Zhangjiakou City contains five major water systems: the Yongding River, Chaobai River, Daqing River, Taiqing River, and Inland River. Chengde City employs the province's three northern rivers (tidal white river, white river, thistle canal), Liaohe, and Daling River as water systems. The total water resources in the Zhangcheng District amount to $5.497 \times 10^{8} \mathrm{~m}^{3}$, of which $4.792 \times 10^{8} \mathrm{~m}^{3}$ are surface water resources, $2.873 \times 10^{8} \mathrm{~m}^{3}$ are groundwater resources, and the double-calculated water volume is $2.169 \times 10^{8} \mathrm{~m}^{3}$. In 2015 , the forest area in the Zhangcheng District was $4.6607 \times 10^{6} \mathrm{hm}^{2}$. Forest resources are rich and diverse and have evident horizontal and vertical distribution rules. There 
are forests, grasslands, farmland, water, and other ecosystems in the area. Forest and grassland ecosystems mainly include Picea asperata Mast, Quercus, Betula, Larix principisrupprechtii Mayr, Pinus sylvestris, and Pinus tabulaeformis Carr, which play a crucial role in water conservation.

a

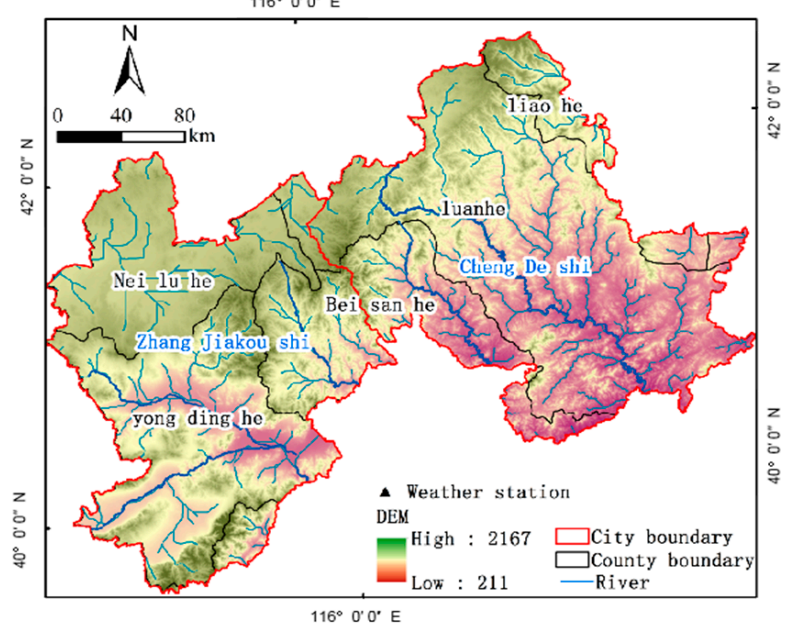

b

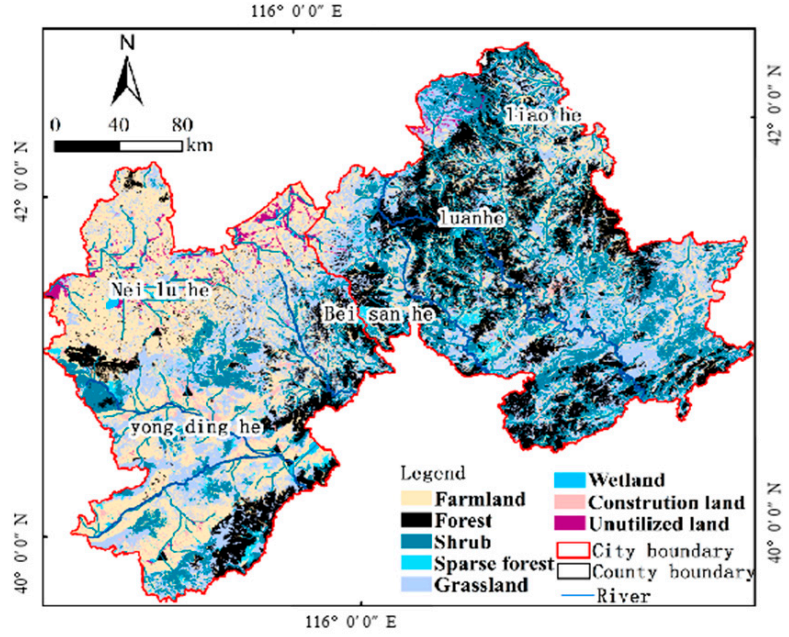

Figure 1. The location (a) and land use type (b) of the study area.

\subsection{InVEST Water Supply Service Model Method}

The InVEST model of water supply service (also known as a water production module) is a raster-based water balance estimation module [32,33]. Moreover, the relationship between climate, terrain factors, and water circulation simplifies the converging process. Assuming that the grid water service reaches the outlet in any of the above ways, the amount of water supplied to each grid cell (including surface production flow, soil water content, dry matter holding capacity, and cover flow) equals the sedimentation. By subtracting the actual evaporation and simulating the spatial distribution of the regional water supply [13,34-36], the specific calculation formula is as follows:

$$
\begin{gathered}
Y_{j x}=\left(1-\frac{A E T_{x j}}{P_{x}}\right) \times P_{x} \\
\frac{A E T_{x j}}{P_{x}}=\frac{1+w_{x} R_{x}}{1+w_{x} R_{x}+\frac{1}{R_{x j}}} \\
w_{x}=\frac{Z \cdot A W C_{x}}{P_{x}} \\
R_{x}=\frac{K_{x j} \cdot E T_{0}}{P_{x}} \\
A W C_{x}=\min \left(M S D_{x}, R D_{x}\right) \times P A W C_{x}
\end{gathered}
$$

Type $Y_{j x}$ is a landscape type $j$ with upper grid unit $x$ annual water supply service $\left(\mathrm{m}^{3}\right) ; A E T_{x j}$ is the type $j$ upper grid unit $x$ annual average evaporation emission; $P_{x}$ is the average annual rainfall of the grid unit $x ; Z$ is the Zhang coefficient, also known as the seasonal factor, which is a constant ranging from 1 to 10 that characterizes the average precipitation characteristics of multiple years determined by the seasonal time distribution and rainfall. For areas where rainfall is concentrated during winter, the $Z$-value tends towards 10, and for areas where rainfall is distributed throughout the year or in summer, the $Z$-value tends towards $1 ; w_{x}$ is a non-physical parameter that characterizes the natural climate-soil properties and is dimensionless; $\mathrm{R} x j$ is the drying index of the grid element 
$x$ on landscape type $j$ and is dimensionless [37]; $A W C_{x}$ is the water content available to plants; $E T_{0}$ is the potential dispersion (mm); $K_{x j}$ is the crop coefficient, which is the ratio of the ET of landscape type $j$ on the grid element $x$ to potential dispersion $E T_{0}$, which is also called the vegetation dispersion coefficient in the model; $M S D_{x}$ is the maximum soil depth; $R D_{x}$ is the root depth; $P A W C_{x}$ is the available water available through indirect calculation of soil texture [38].

\subsection{Data Processing}

InVEST water supply service model input parameters include rainfall, potential evaporation, land use/overburden type, soil thickness, effective soil moisture content, and a biophysical parameter table.

1. Annual rainfall (P) was calculated based on the rainfall data of meteorological stations in and around the Zhangcheng District (18 stations) from 1990 to 2020, and the data from the National Meteorological Science Data Center (http:/ / data.cma.cn/ accessed on 12 August 2021). Using the Kriging method to interpolate rainfall data, the spatial distribution raster data of the average rainfall in the research area for multiple years were obtained (Figure 2a).

2. Potential evaporation $\left(E T_{0}\right)$. The improved Hargreaves formula, one of the simplest empirical formulas for calculating potential steam emission E, was adopted. Using this formula is more reliable when there are more uncertainties than the PenmanMonteith formula [39-43].

$$
E T_{0}=0.003 \times 0.408 \times R A \times\left(T_{a v}+17\right) \times(T D-0.0123 P)^{0.76}
$$

In the improved Hargreaves formula, $T_{a v}$ (in ${ }^{\circ} \mathrm{C}$ ) is the average maximum and lowest temperature per day, TD is the difference between the two temperatures, RA is the astronomical radiation (unit : $\mathrm{MJm}^{-2} \mathrm{~d}^{-2-1}$ ), P represents precipitation (unit : $\mathrm{mm} / \mathrm{month}$ ). Temperature and precipitation data were obtained from the National Meteorological Science Data Center (http:/ / data.cma.cn / accessed on 12 August 2021); RA numbers were obtained by the regression line method of correction (Figure $2 b$ ).

a

$116^{\circ} 0^{\prime} 0^{\prime \prime} \mathrm{E}$

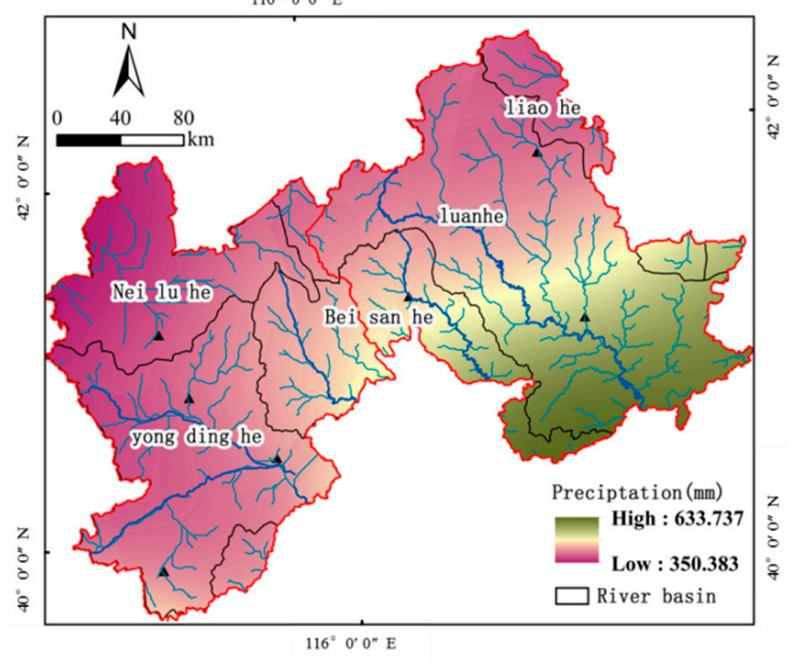

b

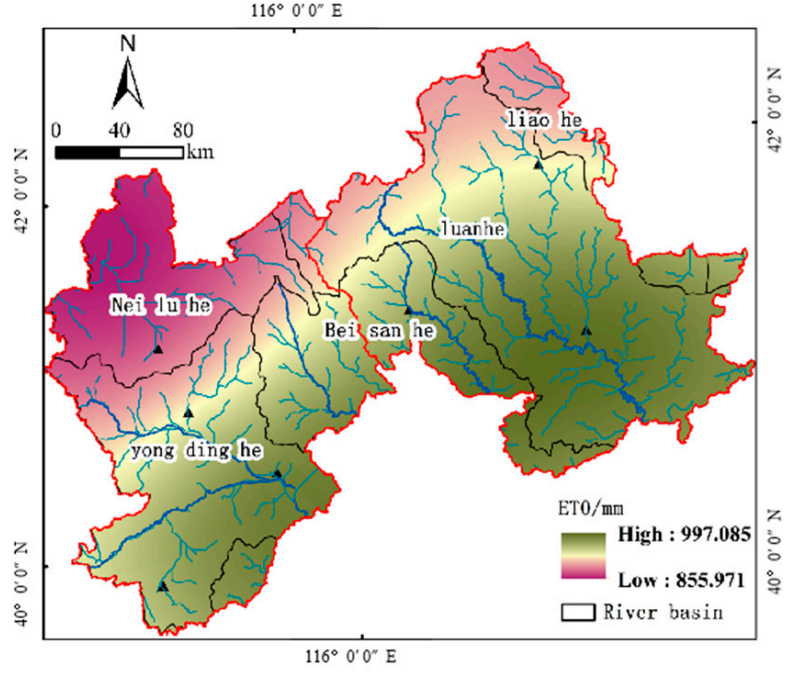

Figure 2. Precipitation (a) and $E T_{0}$ (b) spatial distributions in the Zhangcheng District.

3. Land use type (LUCC) was obtained through the Geographic Data Sharing Infrastructure of the Resource and Environment Science and Data Center (http:/ /www. resdc.cn/, accessed on 12 August 2021). It mainly uses Land-sat remote sensing image data as the primary information source and the land use/land cover remote sensing monitoring database (CNLUCC) established through visual interpretation, 
combined with the actual landscape types of the research area. Here, the land use type was divided into 12 subcategories in six categories, namely cultivated land, forest land (forest land, shrubland, sparse forest land, other woodlands), grassland (high-covered grassland, medium-cover grassland, low-cover grassland), water (river, lake, and reservoir), construction land, and unused land (sandland, bare land, and high Mountain snow-naked rock) (Figure 1b).

4. Water content available to plants (\%). The available water content of plants was calculated using the method proposed by Gupta [38]. The calculation formula is as follows:

$$
\begin{array}{r}
\text { PAWC }=54.509-0.132 \text { sand }-0.003 \text { sand }^{2}-0.055 \text { silt }-0.006 \text { silt } \\
\\
-0.738 \text { clay }+0.007 \text { clay }^{2}-2.688 O M+0.501 \text { M }^{2}
\end{array}
$$

In the formula, sand, silt, and clay represent the content of sand, powder, and clay in the soil (\%), and OM is the organic matter of the soil (\%). Soil data (HWSD V1.2) only provide soil organic carbon content. Therefore, to obtain soil organic matter content, the biommelem coefficient was used to convert soil organic carbon content to soil organic matter content. The above method was used to obtain the water available to plants in the Zhangcheng District (Figure 3).

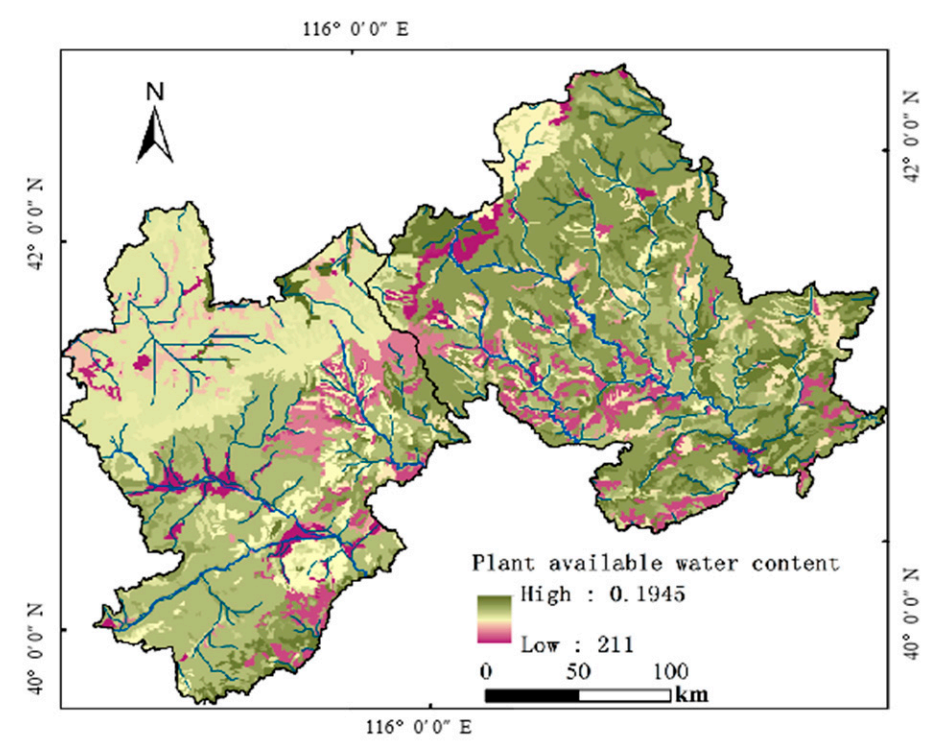

Figure 3. Plant available water content in the Zhangcheng District.

5. Biophysical parameters table. The biophysical parameters table reflects the properties of land use and land cover types in the study area, including land use coding, maximum root depth of vegetation, and evaporation coefficient. The maximum root depth of vegetation data and the dispersion coefficient were obtained from previous research results [41]. Food and Agriculture Organization of the United Nations (FAO) reference values for evapotranspiration coefficients (crop coefficients) (http://www.FAO.org/docrep/x0490E/x0490e00.htm/, accessed on 12 August 2021) and InVEST model database data were generated from dbf data by land use type (landscape type).

\section{Results}

\subsection{Model Parameter Calibration}

It is difficult to accurately verify the prediction results of the model water supply module of InVEST. To verify the accuracy of the simulation results, this study uses Hebei Water Statistics Bulletin data from 1995 to 2015 to determine and validate the relevant parameters of the model; it was used for model parameter calibration in 1995, 2005, and 
2015, and for model validation in 2010 and 2015. The Zhang coefficient is based on the precipitation-runoff relationship to obtain the average natural runoff. It is estimated according to the principle that numerically connects the natural runoff. When the Zhang coefficient is 6.8 , the model simulation depth is the closest to the actual water production depth, and the relative error remains within $20 \%$, indicating that the model parameter calibration is preferable.

\subsection{Model Verification}

This study used the meteorological and land use data of five periods between 1995 and 2015 as input for simulation calculation and compared them with the obtained actual data to verify that the expected model performance was less than $20 \%$ (Table 1 ). The comprehensive verification results show that in 20 years, the total simulated water production volume and the actual water production in Zhangjiakou City and Chengde City in 2015 are $7.73 \%$ and $4.83 \%$, respectively, with an error of $3.73 \%$ for Chengde City and $0 \%$ in Zhangjiakou City. Thus, the InVEST model has good simulation accuracy, the parameter effect is more robust, and it can estimate the water production volume in the Zhangcheng District.

Table 1. Annual water yield model result verification of the InVEST model.

\begin{tabular}{|c|c|c|c|c|c|}
\hline $\begin{array}{c}\text { Model } \\
\text { Accuracy } \\
\text { Verification }\end{array}$ & Year & City & $\begin{array}{c}\text { Simulated } \\
\text { Water Depth } \\
(\mathrm{mm})\end{array}$ & $\begin{array}{l}\text { Actual Water } \\
\text { Depth (mm) }\end{array}$ & $\begin{array}{c}\text { Relative } \\
\text { Error (\%) }\end{array}$ \\
\hline \multirow{6}{*}{$\begin{array}{l}\text { Corrected } \\
\text { parameter }\end{array}$} & \multirow{2}{*}{1995} & Zhangjiakou & 42.63 & 36.76 & 15.97 \\
\hline & & Chengde & 42.96 & 42.29 & 12.20 \\
\hline & \multirow{2}{*}{2000} & Zhangiiakou & 44.14 & 37.32 & 18.27 \\
\hline & & Chengde & 46.04 & 44.69 & 13.18 \\
\hline & \multirow{2}{*}{2005} & Zhangiiakou & 43.57 & 37.88 & 15.01 \\
\hline & & Chengde & 44.76 & 40.64 & 10.14 \\
\hline \multirow{4}{*}{$\begin{array}{l}\text { Verified } \\
\text { result }\end{array}$} & \multirow{2}{*}{2010} & Zhangjiakou & 43.10 & 46.00 & 6.30 \\
\hline & & Chengde & 45.48 & 47.20 & 3.64 \\
\hline & \multirow{2}{*}{2015} & Zhangjiakou & 42.20 & 42.20 & 0.00 \\
\hline & & Chengde & 44.80 & 38.90 & 3.73 \\
\hline
\end{tabular}

3.3. Characteristics of Spatial-Temporal Distribution of Water Supply Services in Zhangcheng District

Figure 4 shows that the spatial distribution pattern of water supply services in the Zhangcheng District has minor changes and generally shows regularity. The high-value water supply service zones are concentrated in Huai'an County, Guyuan County, Zhangjiakou City, Xinglong County, and Pingquan County, southern Chengde City. The average water supply service is between 60 and $85 \mathrm{~mm}$; on both sides of the Yanshan-Tahang Mountains, the average water supply service is between 31 and $59 \mathrm{~mm}$. Located in Yanshan-Taihang Mountains, Weichang County, Longhua County, and Zhuolu County, the average water supply service is relatively small, with $20 \sim 30 \mathrm{~mm}$. This distribution pattern is related directly to the average annual precipitation and vegetation distribution in the Zhangcheng District. In other words, the regions with high annual precipitation and low vegetation evaporation have a strong water supply capacity. In terms of time, the average water production during the study tended to increase and then decrease; the total water production in Zhangjiakou and Chengde cities increased from $15.60 \times 10^{8} \mathrm{~m}^{3}$ and $16.84 \times 10^{8} \mathrm{~m}^{3}$ in 1995 a to $15.94 \times 10^{8} \mathrm{~m}^{3}$ and $17.55 \times 10^{8} \mathrm{~m}^{3}$ in 2005 , and then decreased to $15.45 \times 10^{8} \mathrm{~m}^{3}$ and $17.60 \times 10^{8} \mathrm{~m}^{3}$ in 2015 . 

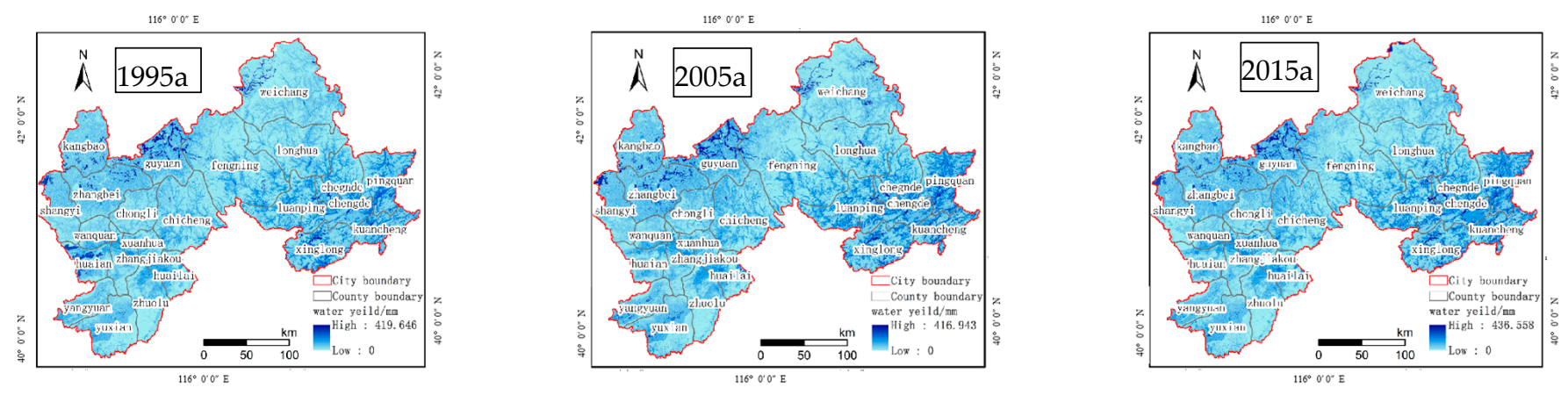

Figure 4. Spatial-temporal distribution of water supply service in the Zhangcheng.

\subsection{Distribution Characteristics of Water Yield in the Zhangcheng District by River Basin}

In 2014, General Secretary Xi repeatedly mentioned that during the coordinated development of Beijing, Tianjin, and Hebei, in order to ensure national water security, it is necessary to strengthen the development of the Zhangcheng water conservation area and comprehensively repair and protect the water ecological environment in the Zhangcheng District. The vast majority of the Zhangcheng District belongs to the Haihe River Basin and has evident watershed connectivity. The average water production in different watersheds in the Zhangcheng District varies with time. Spatially, the average water production is manifested as inland river $>$ Liaohe $>$ capital bank $>$ Yongding River $>$ Daqing River (Figure 5a). The total water production and the average water production are similar in time, and this is spatially reflected in the capital management industry $>$ Yongding River $>$ Inland River > North Three Rivers > Liaohe River > Daqing River Basin (Figure 5b).

a

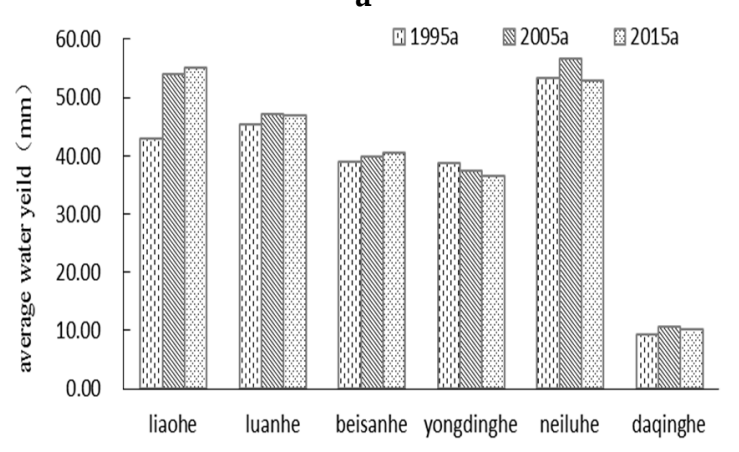

b

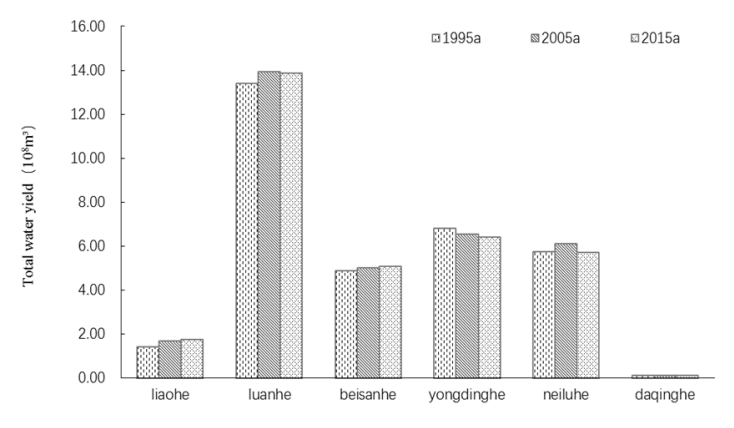

Figure 5. Average (a) and Total annual (b) water supply in different river basins in the Zhangcheng District.

\subsection{Water Yield Distribution Characteristics of Main Vegetation Types in the Zhangcheng District}

The vegetation classification map of the research area was obtained from the Resource and Environmental Science and Data Center of the Chinese Academy of Sciences (https: / / www.resdc.cn/1995,2005,2015, accessed on 12 August 2021). ArcGIS spatial analysis was used to carry out zoning statistics on the water supply and service capabilities of various vegetation landscape types. The research areas were obtained in 1995 . Twenty average (Figure 6a) and total water supply (Figure 6b) were obtained in the third phase of the three vegetation types in 2015. In 1995, the average water supply of each vegetation landscape was in the order: meadow $>$ coniferous forest $>$ other vegetation type $>$ cultivated vegetation $>$ grassland $>$ shrub $>$ grass $>$ broadleaf forest. In 2005, the average water supply of vegetation landscapes was roughly similar to that of 1995. In 2015, coniferous forests had the largest average water supply across the vegetated landscape, followed by grassland and other vegetation types and cropland vegetation, while broadleaf forests remained the lowest. From the perspective of the total water supply, the cultivated landscape plays a leading role. The overall performance is as follows: the farmland ecosystems have the largest total water production, accounting for more than $49 \%$ of the total water supply; the 
thicket and grasslands account for around 30\%, and coniferous forests and other vegetation types' contributions are relatively small (Figure 6b). In the past 20 years, the coniferous forest, broadleaf tree forest, and meadow water supply services have shown a trend of growth followed by a decrease, with shrubs and grasslands showing an annual growth trend; the grasslands' water source supply has declined annually.

a

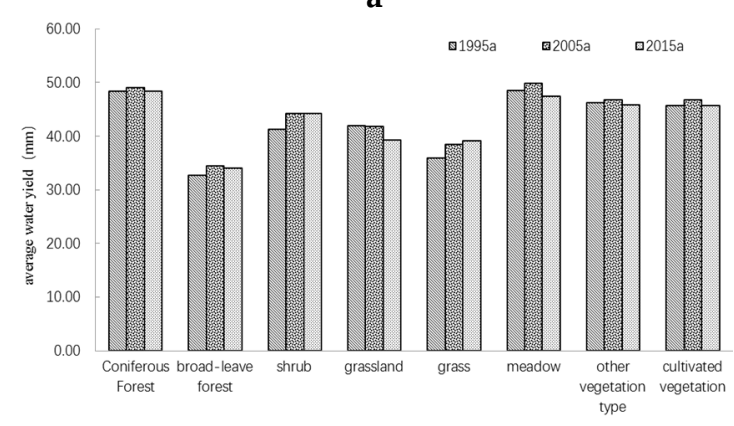

b

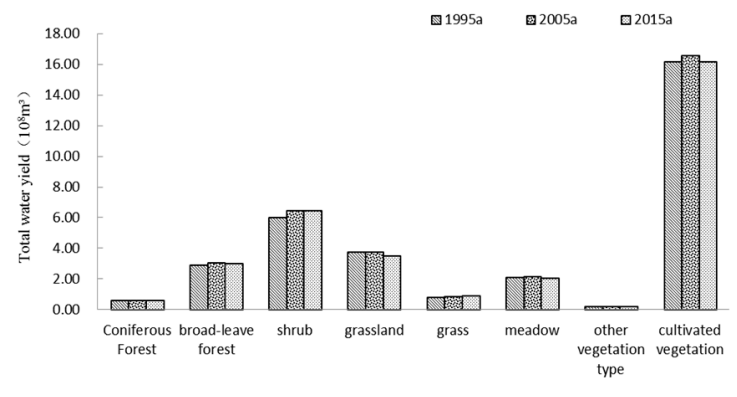

Figure 6. Twenty average (a) and total annual (b) water supply in different vegetation type areas in the Zhangcheng District.

\subsection{The Influence of Topographic Factors on Water Yield in Zhangcheng District}

Topographic factors affecting water supply services in the Zhangcheng District were analyzed from three aspects: altitude, slope, and slope direction. First of all, according to the actual situation of the study area with a large altitude difference, steep peaks and high slopes, and rolling mountains, the elevation of the basin was divided into seven levels: $<300$, 300 1500, 500 1000, 1000 1500, 1500 2000, 2000 2500, and $\geq 2500 \mathrm{~m}$. Research shows that the average water production gradually decreases with altitude (Figure 7a); the total amount of water resources is spaced, and the total water supply in the river basin increases with altitude; in areas above $1500 \mathrm{~m}$, the water supply begins to rise with altitude. The regional water supply is primarily concentrated in the altitude range of 500-1500 m, accounting for more than $70 \%$ of the total water supply, while the total water supply in areas below $300 \mathrm{~m}$ and above $1500 \mathrm{~m}$ is relatively small (Figure 7b). Between 1995 and 2015, the total amount of water resources generally showed a rising trend followed by a decline, but the overall change was relatively small.

a

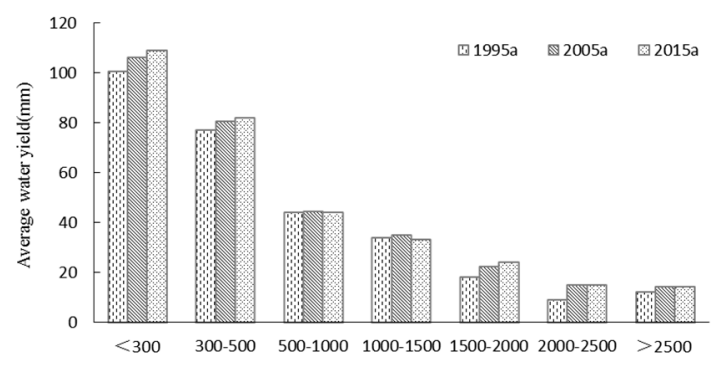

b

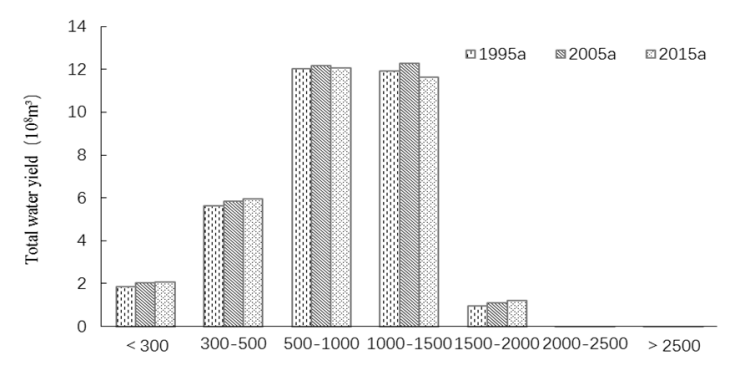

Figure 7. The distribution of average (a) and total (b) water supply service at different elevations in the Zhangcheng District.

DEM was used to extract and grade the slopes in the research area and statistically analyze the water supply distribution in the basin at different slopes (Figure 8). Between 1995 and 2015, spatially, the average water production in the Zhangcheng District increased gradually with the increase in slopes. In terms of time, the changing trend is consistent within different slopes, showing an increasing and decreasing trend. The Zhangcheng District's total water supply is mainly concentrated in the $<15^{\circ}$ slopes, accounting for more than $49 \%$ of the water supply in the study area. In the slope range of $<5^{\circ}$, the water supply in the basin is relatively small. The main reason for this situation is closely related to the grid data of different slopes. 
a

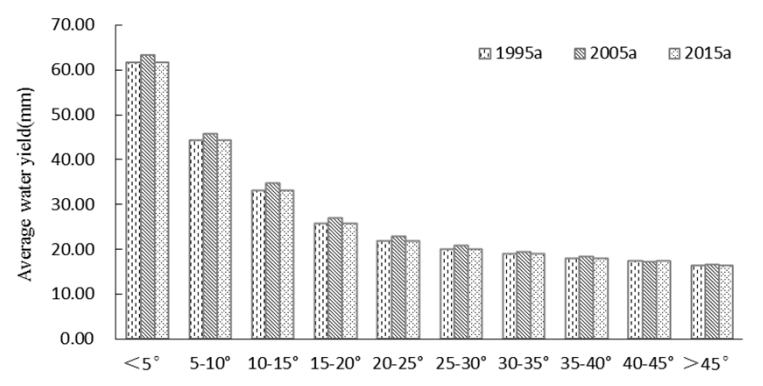

b

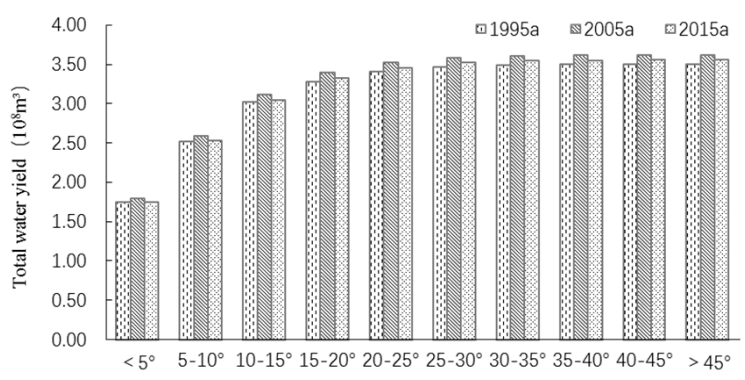

Figure 8. The distribution of average (a) and total (b) water supply service at different gradients of slopes in the Zhangcheng District.

Figure 9 shows that the water output slopes of the Zhangcheng District are slightly different, but the overall water supply of the sunny slopes is slightly larger than that of the shady slopes. The average water supply volume of shady and sunny slopes is 43.35 and $43.63 \mathrm{~mm}$, respectively, and the total water supply in the basin can be expressed as shady slope $>$ sunny slope $>$ half sunny slope $>$ half shady slope. In terms of time, between 1995 and 2015, slopes generally showed a trend of slight growth before decreasing.

a

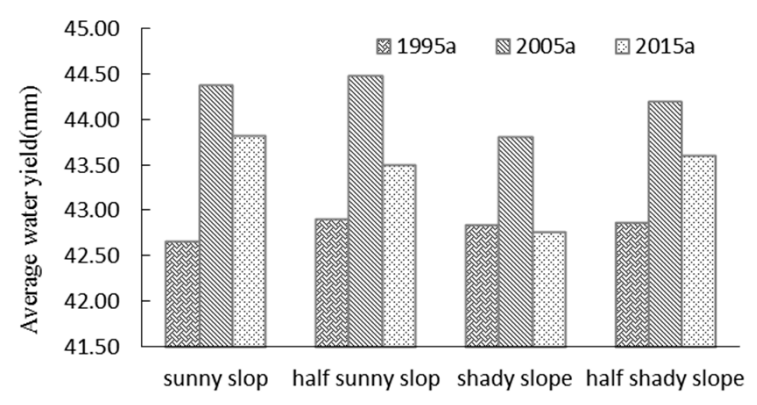

b

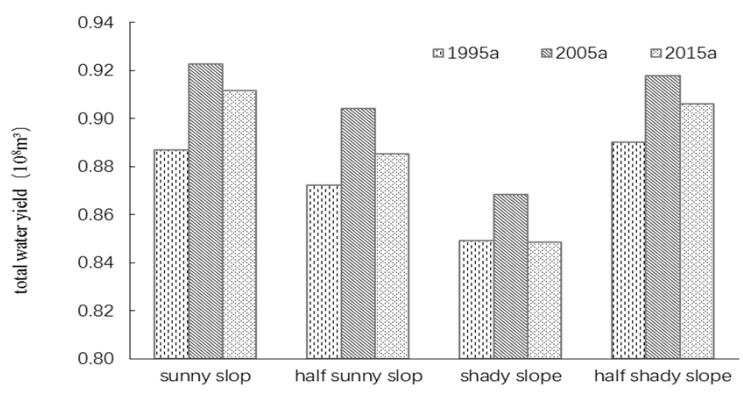

Figure 9. The distribution of average (a) and total (b) water supply service for different slope aspects in the Zhangcheng District.

\subsection{Analysis of Drivers of Change in Water Production}

The impact of climate change on water production in the Zhangcheng District draws a correlation between the depth of water production, precipitation, and evaporation (Figure 10). Over the years, the average depth of water production has been positively correlated with the average precipitation. The potential evaporation emission is negatively correlated, consistent with Li Yiying, Yang Ying, Li Yingying, Wang Culting, and Han Dongxue, and contrary to Gong Shihan. The research conclusions of a positive correlation between water source conservation and evaporation emission are biased. The changing trend of average water production depth and precipitation in this study is the same. The years in which the extremes occur correspond to precipitation extremes, but there are significant deviations from the potential evapotranspiration emission trends, indicating that precipitation is the main factor influencing water production. 


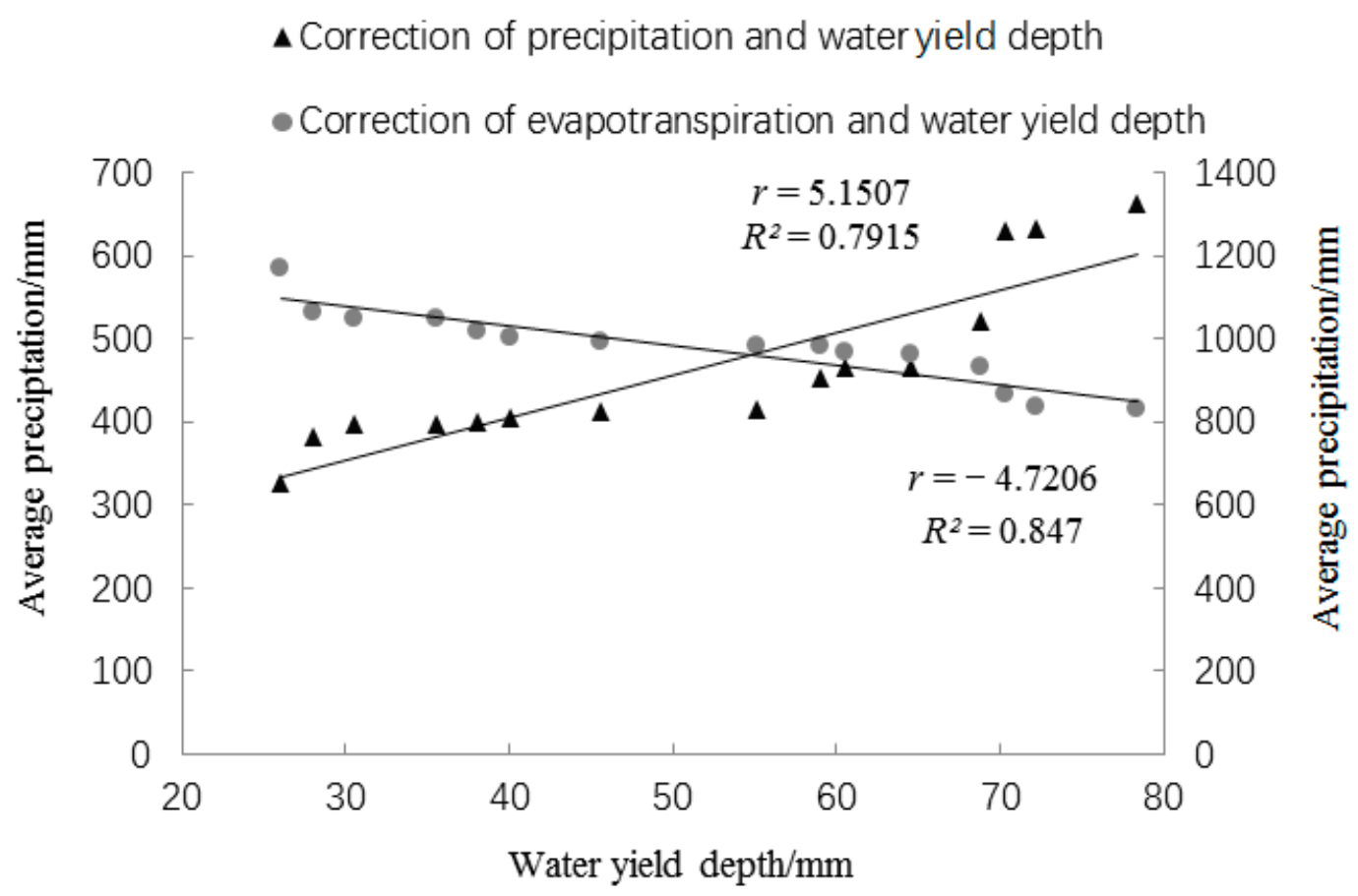

Figure 10. Correlations of annual average water yield with precipitation and potential evapotranspiration in the Zhangcheng District.

\subsection{The Influence of Topographic Factors on Water Production in the Zhangcheng District}

A correlation between water production depth and different altitudes and slopes was established (Figure 11). In the range of 0-1200 m, the average water production depth is significantly negatively correlated with altitude $\left(r=-0.0903, R^{2}=0.9528\right)$; in the range of $>1300 \mathrm{~m}$, there is a negative correlation with altitude $\left(r=-0.0173, R^{2}=0.8262\right)$, but the trend is relatively flat. Surface runoff has a cumulative effect in the area, which has great potential for runoff formation, so the water production volume change is negatively related to altitude. The correlation between slope and water yield change is the same as that of elevation. In a range lower than $25^{\circ}$, the average water production is significantly negatively correlated with the slope $\left(r=-9.8983, R^{2}=0.9352\right)$; in a range greater than $25^{\circ}$, the average water production negatively correlates with the slope $\left(r=-0.9552, R^{2}=0.9932\right)$, and the trend is relatively smooth.

a

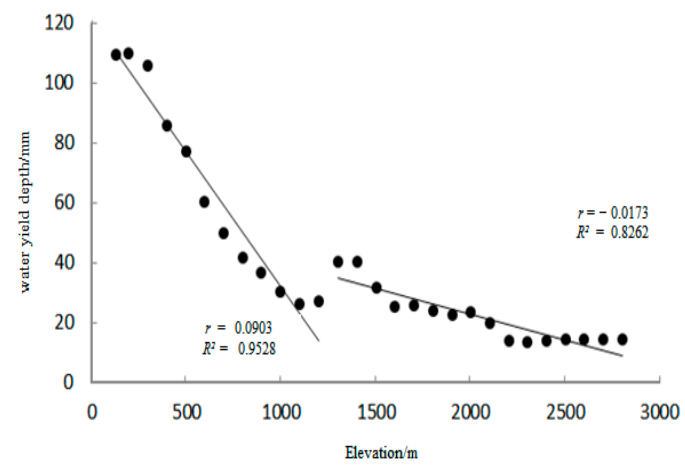

b

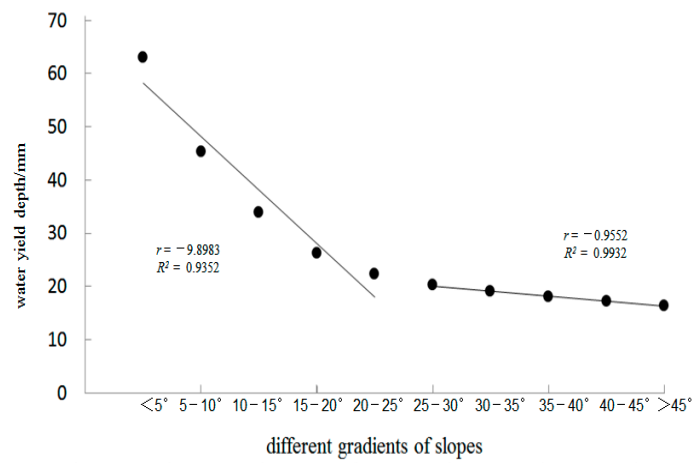

Figure 11. Correlations of annual average water yield with different elevations (a) and gradients of slopes (b) in the Zhangcheng District. 


\subsection{The Impact of Land Use Change on Water Production in Zhangcheng District}

Land use is the most critical data source of the InVEST water production model and one of the key factors affecting water production. Table 2 shows noticeable differences in yearly water production between 1995 and 2015, which may be caused by different regional geographical differences, consistent with the results of [35,43], such as in the ZhangjiakouSchengde region [38] and Shiyang River basin. Statistics on the various land use changes caused over the years, their contribution to water production and conservation, and water production and conservation changes are presented in Table 2. The overall land use change from 1995 to 2015 is as follows: construction land, sparse forest land, grassland, shrubs, woodland, cultivated land. As a result, the water production in construction land and cultivated land has been reduced. Although the area is large, due to the low conservation capacity of construction land and unused land water sources, the contribution to water production is still small. The main reason for the decrease in the overall area of grassland and the increase in water production may be the overall increase in water production due to the increase in regional precipitation over the years. Moreover, the dynamic change in unused land in Zhangjiakou over the years-that is, the unused land area in areas with less precipitation, such as Kangbao and Guyuan — and the decrease in Huailai might influence this decrease. Unused land increases in areas with more water, so areas with more precipitation produce more water than areas with less precipitation. In terms of water production, the most productive areas are cultivated land and grassland, followed by shrubs, construction land, and woodland. Due to the small amount of precipitation in the Zhangjiakou area, the evaporation and emission of forest land are too large, thus reducing water production.

Table 2. Changes in water yield caused by various land uses in Zhangcheng District over several years.

\begin{tabular}{|c|c|c|c|c|c|}
\hline \multirow{2}{*}{ Type } & \multicolumn{3}{|c|}{ Water Yield Contribution (\%) } & \multicolumn{2}{|c|}{ Variation $(\%)$} \\
\hline & 1995a & 2005a & $2015 a$ & Area $/ \mathrm{km}^{2}$ & Water Yield $/\left(\times 10^{8} \mathrm{~m}^{3}\right)$ \\
\hline Farmland & 50.84 & 54.36 & 51.38 & -7.48 & -2.99 \\
\hline Forest & 4.79 & 2.82 & 2.78 & 10.02 & 40.84 \\
\hline Shrub & 9.26 & 4.98 & 4.13 & 11.94 & 54.55 \\
\hline Sparse forest & 2.50 & 0.62 & 0.53 & 73.50 & 78.55 \\
\hline Grassland & 23.03 & 23.20 & 21.90 & -23.37 & 3.07 \\
\hline Construction land & 5.64 & 5.17 & 12.29 & -105.70 & -122.00 \\
\hline Unutilized land & 3.94 & 8.84 & 7.00 & -73.31 & -81.04 \\
\hline
\end{tabular}

\section{Discussion}

1. Between 1995 and 2015, the water supply service in the Zhangcheng District showed a trend of first increasing and then slightly decreasing, and the distribution pattern showed minor changes. This phenomenon is related to watershed meteorological factors (such as precipitation and potential evaporation) and the distribution area of the vegetation distribution pattern from a vegetation landscape type. Precipitation in the watershed of the Zhangcheng District is the primary source of ecosystem water circulation, and potential evaporation indirectly reflects the water consumption capacity of regional ecosystems [35,42]; the bottom surface state and its spatial distribution also affect the distribution pattern of the water supply capacity of watershed ecosystems [44]. Regarding spatial distribution, areas with a high water supply in the Zhangcheng District are mainly distributed in mountainous forest areas with abundant rainfall and lush forest growth, such as Fengning Manchu Autonomous Region, Longhua County, and Waichang County, located in the Yanshan-Taihang Mountains. Although these areas have relatively high rainfall, the air is relatively humid. Coniferous forests have low evapotranspiration and high water production. When old coniferous forests are cut, planted forests and secondary forests do not proliferate, and the water production volume in river basins increases. However, 
over time, vegetation growth and restoration entered a mixed growth stage involving shrubs, secondary broadleaf forests, mixed coniferous forests, artificial spruce forests, a forest cover increase, and a water production decline [45-47]. Under the same climatic background, the water supply in the river basin decreased with the restoration of vegetation and the expansion of the proportion of forest land. This phenomenon and its distribution pattern are similar to those in areas such as bridge reservoirs [48], the upper reaches of Miyun reservoirs [49,50], the Lancang River basin [51], or water supply distribution patterns. However, the distribution of the parallel area of the Three Rivers [52] is slightly different, mainly manifested in ice and snow glaciers. This is mainly because the parallel area of the Three Rivers belongs to the high-altitude zone, and the ice and snow cover is extensive, so its water production is high. The Zhangcheng District is relatively unaffected by ice and snow glaciers and has primarily seasonal snow accumulation produced in the basin. The influence of the water process is relatively weak. In addition, the ability of the ecosystem to intercept rainfall is weak, the root system is shallow, and the cultivated area is large, so the total supply of farmland water is relatively large.

2. Among different topographic factors, the average water production in the Zhangcheng District decreases with the increase of altitude and slope, and the water supply to the shadowed slope is greater than that of the sunny slope. This is similar to the results of other scholars [53] and is mainly influenced by the characteristics of rainfall and topographic differences. The highest precipitation is found at elevations of 500-1500 m. In the windward slope area, the forest is widely distributed, the topographic rain characteristics are apparent, and the potential evaporation is not large. For example, there are scattered trees such as deciduous broad-green broadleaf forests and broadleaf mixed forests, and the forest water source has a strong conservation capacity, so the water supply is large. In Kangbao, Zhangbei, Shangyi, and other places in the plateau area of the dam, in addition to cultivated land, there are also industrial and mining lands, residential land, and other construction lands. Because the total area is minimal, the total water supply is relatively small. At the same time, these areas have crossed the forest line of most forest vegetation, and the surface vegetation landscape has gradually been irrigated with grassland and cold grassland. Alpine sparse vegetation and bare rock are replaced by relatively little rainfall and the weak conservation capacity of vegetation sources, so its water supply is relatively small.

\section{Conclusions}

1. In the Zhangcheng District ecosystem, the average water supply is approximately $43.5 \mathrm{~mm}$, which shows a certain regularity in space. The high-value areas are mainly distributed in the mountain forest areas, with the most prominent water conservation forests in the dams of Yanshan-Tahang Mountain. Most low-value areas are concentrated in the upper plains or altitudes of dams with low rainfall and frequent human activities. From the perspective of land use type, the water production capacity of the farmland ecosystem in the Zhangcheng District is relatively high. In terms of time, the water supply services in the basin show a trend of initial growth and then a slight decrease.

2. The overall water supply in the Zhangcheng District tends to rise first and then decrease with the altitude increase. The water supply in the areas with steep slopes is slightly higher than in areas with mild slopes, and the high-value areas appear at 500-1500 $\mathrm{m}$ and $300-500^{\circ}$, respectively; the water supply volume of Yin and Yangpo is greater than that of the half-yang slope and half-yin slopes.

3. The introduction of the InVEST model provides a feasible method for estimating the spatial distribution of water supply services in large- and medium-scale regions. However, there may be uncertainties in the study results due to the simplified model structure and methodology and the lack of large field stations and long-term experimental observation data in the study area. Qualitatively, it is suggested that in future 
research, based on the evaluation model and its parameter suitability, the observation, localization, and verification of field data should be further strengthened, focusing on developing China's localized evaluation model to ensure the credibility and reliability of the evaluation results.

Author Contributions: Conceptualization, R.L. and B.W.; methodology, R.L.; software, R.L.; validation B.W., X.N. and Q.S.; formal analysis, R.L.; investigation, R.L; resources, Q.S. and R.L.; data curation, Q.S.; writing —original draft preparation, R.L.; writing-review and editing, R.L.; B.W., X.N.; visualization, R.L.; supervision, X.N. and Q.S.; project administration, X.N.; funding acquisition, X.N. All authors have read and agreed to the published version of the manuscript.

Funding: This research was funded by the Central Non-profit Research Institution of CAF, grant number CAFYBB2020ZE003 and CAFYBB2020ZD002-2; Ecological positioning observation and ecological function calculation of national public welfare forest construction effectiveness monitoring and evaluation, grant number 2130207-20-201/107.

Conflicts of Interest: The authors declare no conflict of interest.

\section{References}

1. Li, M.; Liang, D.; Xia, J.; Song, J.; Cheng, D.; Wu, J.; Cao, Y.; Sun, H.; Li, Q. Evaluation of water conservation function of Danjiang River Basin in Qinling Mountains, China based on InVEST model. J. Environ. Manag. 2021, 286, 112-212. [CrossRef]

2. Li, X.; Niu, J.; Xie, B. Study on hydrological functions of litter layers in North China. PLoS ONE 2013, 8, e70328. [CrossRef]

3. Du, J.; Niu, J.Z.; Gao, Z.L.; Chen, X.W.; Zhang, L.; Li, X.; van Doorn, N.S.; Luo, Z.T.; Zhu, Z.J. Effects of rainfall intensity and slope on interception and precipitation partitioning by forest litter layer. Catena 2019, 172, 711-718. [CrossRef]

4. Biao, Z.; Wenhua, L.; Gaodi, X.; Yu, X. Water conservation of forest ecosystem in Beijing and its value. Ecol. Econ. 2010, 69, 1416-1426. [CrossRef]

5. Zhu, H.; Wang, G.; Yinglan, A.; Liu, T. Ecohydrological effects of litter cover on the hillslope-scale infiltration-runoff patterns for layered soil in forest ecosystem. Ecol. Eng. 2020, 155, 105930. [CrossRef]

6. Fischer, J.; Lindenmayer, D.B.; Manning, A.D. Biodiversity, ecosystem function, and resilience: Ten guiding principles for commodity production landscapes. Front. Ecol. Environ. 2006, 4, 80-86. [CrossRef]

7. Snelgrove, P.V. Getting to the bottom of marine biodiversity: Sedimentary habitats: Ocean bottoms are the most widespread habitat on earth and support high biodiversity and key ecosystem services. Bio-Science 1999, 49, 129-138.

8. Long, H.; Tang, G.; Li, X.; Heilig, G.K. Socio-economic driving forces of land-use change in Kun-shan, the Yangtze River Delta economic area of China. J. Environ. Manag. 2007, 83, 351-364. [CrossRef]

9. Jiang, Y. China's water scarcity. J. Environ. Manag. 2009, 90, 3185-3196. [CrossRef]

10. Varis, O.; Vakkilainen, P. China's 8 challenges to water resources management in the first quarter of the 21st Century. Geomorphology 2001, 41, 93-104. [CrossRef]

11. Wealands, S.R.; Grayson, R.B.; Walker, J.P. Quantitative comparison of spatial fields for hydro-logical model assessment--some promising approaches. Adv. Water Resour. 2005, 28, 15-32. [CrossRef]

12. Larsen, L.G.; Choi, J.; Nungesser, M.K.; Arvey, J.W. Directional connectivity in hydrology and ecology. Ecol. Appl. 2012, 22, 2204-2220. [CrossRef]

13. Hoyer, R.; Chang, H. Assessment of freshwater ecosystem services in the Tualatin and Yamhill basins under climate change and urbanization. Appl. Geogr. 2014, 53, 402-416. [CrossRef]

14. Hargrove, W.W.; Hoffman, F.M. Potential of multivariate quantitative methods for delineation and visualization of ecoregions. Environ. Manag. 2004, 34, S39-S60. [CrossRef]

15. Golmohammadi, G.; Prasher, S.; Madani, A.; Rudra, R. Evaluating three hydrological distributed watershed models: MIKE-SHE, APEX, SWAT. Hydrology 2014, 1, 20-39. [CrossRef]

16. Chen, S.; Wen, Z.; Jiang, H.; Zhao, Q.; Zhang, X.; Chen, Y. Temperature vegetation dryness index estimation of soil moisture under different tree species. Sustainability 2015, 7, 11401-11417. [CrossRef]

17. Neitsch, S.L.; Arnold, J.G.; Kiniry, J.R.; Williams, J.R. Soil and Water Assessment Tool Theoretical Documentation Version 2009; Texas Water Resources Institute: College Station, TX, USA, 2011.

18. Mishra, S.K.; Singh, V.P. Soil Conservation Service Curve Number (SCS-CN) Methodology; Springer Science \& Business Media: Berlin/Heidelberg, Germany, 2013; Volume 42.

19. Guerry, A.D.; Ruckelshaus, M.H.; Arkema, K.K.; Bernhardt, J.R.; Guannel, G.; Kim, C.K.; Marsik, M.; Papenfus, M.; Verutes, G.; Beck, M.; et al. Modeling benefits from nature: Using ecosystem services to inform coastal and marine spatial planning. Int. J. Biodivers. Sci. Ecosyst. Serv. Manag. 2012, 8, 107-121. [CrossRef]

20. De Groot, R.S.; Alkemade, R.; Braat, L.; Hein, L.; Willemen, L. Challenges in integrating the con-cept of ecosystem services and values in landscape planning, management and decision making. Ecol. Complex. 2010, 7, 260-272. [CrossRef] 
21. Ouyang, Z.; Zheng, H.; Xiao, Y.; Polasky, S.; Liu, J.; Xu, W.; Daily, G.C. Improvements in ecosys-tem services from investments in natural capital. Science 2016, 352, 1455-1459. [CrossRef]

22. Tallis, H.T.; Ricketts, T.; Nelson, E.; Wolny, S.; Olwero, N.; Vigerstol, K.; Pennington, D.; Mendoza, G.; Aukema, J.; Foster, J.; et al. InVEST 2.5.4 User' s Guide; The Natural Capital Project: Stanford, CA, USA, 2013.

23. Ismail, M.S.; Moghavvemi, M.; Mahlia, T.M.I. Characterization of PV panel and global optimi-zation of its model parameters using genetic algorithm. Energy Convers. Manag. 2013, 73, 10-25. [CrossRef]

24. Schulp, C.J.; Lautenbach, S.; Verburg, P.H. Quantifying and mapping ecosystem services: De-mand and supply of pollination in the European Union. Ecol. Indic. 2014, 36, 131-141. [CrossRef]

25. Goldstein, J.H.; Caldarone, G.; Duarte, T.K.; Ennaanay, D.; Hannahs, N.; Mendoza, G.; Polasky, S.; Wolny, S.; Daily, G.C. Inte-grating ecosystem-service tradeoffs into land-use decisions. Proc. Natl. Acad. Sci. USA 2012, 109, 7565-7570. [CrossRef]

26. Bagstad, K.J.; Semmens, D.J.; Winthrop, R. Comparing approaches to spatially explicit ecosystem service modeling: A case study from the San Pedro River, Arizona. Ecosyst. Serv. 2013, 5, 40-50. [CrossRef]

27. Li, S.; Gu, S.; Liu, W.; Han, H.; Zhang, Q. Water quality in relation to land use and land cover in the upper Han River Basin, China. Catena 2008, 75, 216-222. [CrossRef]

28. Lü, L.; Ren, T.; Sun, C.; Zheng, D.; Wang, H. Spatial and temporal changes of water supply and water conservation function in Sanjiangyuan National Park from 1980 to 2016. Acta Ecol. Sin. 2020, 40, 993-1003.

29. Arnold, J.G. Spatial Scale Variability in Model Development and Parameterization. Ph.D. Thesis, Purdue University, West Lafayette, IN, USA, 1992.

30. Duan, L.; Huang, M.; Zhang, L. Differences in hydrological responses for different vegetation types on a steep slope on the Loess Plateau, China. J. Hydrol. 2016, 537, 356-366. [CrossRef]

31. Redhead, J.W.; Stratford, C.; Sharps, K.; Jones, L.; Ziv, G.; Clarke, D.; Bullock, J.M. Empirical validation of the InVEST water yield ecosystem service model at a national scale. Sci. Total Environ. 2016, 569, 1418-1426. [CrossRef] [PubMed]

32. Hamel, P.; Guswa, A.J. Uncertainty analysis of a spatially explicit annual water-balance model: Case study of the Cape Fear basin, North Carolina. Hydrol. Earth Syst. Sci. 2015, 19, 839-853.

33. Zhang, L.; Dawes, W.R.; Walker, G.R. Response of mean annual evapotranspiration to vegetation changes at catchment scale. Water Resour. Res. 2001, 37, 701-708. [CrossRef]

34. Leh, M.D.; Matlock, M.D.; Cummings, E.C.; Nalley, L.L. Quantifying and mapping multiple ecosystem services change in West Africa. Agric. Ecosyst. Environ. 2013, 165, 6-18. [CrossRef]

35. Francesconi, W.; Srinivasan, R.; Pérez-Miñana, E.; Willcock, S.P.; Quintero, M. Using the Soil and Water Assessment Tool (SWAT) to model ecosystem services: A systematic review. J. Hydrol. 2016, 535, 625-636. [CrossRef]

36. Fisher, B.; Turner, R.K.; Burgess, N.D.; Swetnam, R.D.; Green, J.; Green, R.E.; Kajembe, G.; Kulindwa, K.; Lewis, S.L.; Marchant, R.; et al. Measuring, modeling and mapping ecosystem services in the Eastern Arc Mountains of Tanzania. Prog. Phys. Geogr. 2011, 35, 595-611. [CrossRef]

37. Donohue, R.J.; Roderick, M.L.; McVicar, T.R. Roots, storms and soil pores: Incorporating key ecohydrological processes into Budyko's hydrological model. J. Hydrol. 2012, 436, 35-50. [CrossRef]

38. Gupta, S.; Larson, W.E. Estimating soil water retention characteristics from particle size distribu-tion, organic matter percent, and bulk density. Water Resour. Res. 1979, 15, 1633-1635. [CrossRef]

39. Hargreaves, G.H.; Samani, Z.A. Estimating potential evapotranspiration. J. Irrig. Drain. Div. 1982, 108, 225-230. [CrossRef]

40. Hamon, W.R. Estimating potential evapotranspiration. Trans. Am. Soc. Civ. Eng. 1963, 128, 324-338. [CrossRef]

41. Canadell, J.; Jackson, R.B.; Ehleringer, J.B.; Mooney, H.A.; Sala, O.E.; Schulze, E.D. Maximum rooting depth of vegetation types at the global scale. Oecologia 1996, 108, 583-595. [CrossRef] [PubMed]

42. Xiao, R.B.; Ouyang, Z.Y.; Zheng, H.; Li, W.F.; Schienke, E.W.; Wang, X.K. Spatial pattern of impervious surfaces and their impacts on land surface temperature in Beijing, China. J. Environ. Sci. 2007, 19, 250-256. [CrossRef]

43. Allen, R.G.; Pereira, L.S.; Raes, D.; Smith, M. Crop Evapotranspiration-Guidelines for Computing Crop Water Requirements-FAO Irrigation and Drainage Paper 56; FAO: Rome, Italy, 1998; Volume 300, p. D05109.

44. Wang, Y.; Xiao, H.L.; Lu, M.F. Analysis of water consumption using a regional input-output model: Model development and application to Zhangye City, Northwestern China. J. Arid Environ. 2009, 73, 894-900. [CrossRef]

45. Zhang, Y.; Liu, S.; Gu, F. The impact of forest vegetation change on water yield in the subalpine region of southwestern China. Acta Ecol. Sin. 2011, 31, 7601-7608.

46. Bosch, J.M.; Hewlett, J.D. A review of catchment experiments to determine the effect of vege-tation changes on water yield and evapotranspiration. J. Hydrol. 1982, 55, 3-23. [CrossRef]

47. Hibbert, A.R. Forest Treatment Effects on Water Yield; Coweeta Hydrologic Laboratory, Coweeta Hydrologic Laboratory, Southeastern Forest Experiment Station: Asheville, NC, USA, 1965.

48. Sun, Y.; Li, J.; Ma, R.; Li, W. Style of spatial distribution of water supply service in Yuqiao watershed. J. Water Resour. Water Eng. 2015, 6. [CrossRef]

49. Wang, F.; Zheng, H.; Wang, X.; Peng, W.; Ma, D.; Li, C. Classification of the relationship between household welfare and ecosystem reliance in the Miyun Reservoir Watershed, China. Sustainability 2017, 9, 2290. [CrossRef]

50. Lang, X. Impacts of Different Forest Watershed Composition Factors on Soil Condition in Upstream of Miyun Reservoir Watershed, Nothern China and Its Current Situation. Ph.D. Thesis, Lakehead University, Thunder Bay, ON, Canada, 2020. 
51. Long, C.; Gaodi, X.; Changshun, Z.; Sha, P.; Na, F.; Liqiang, G.; Caixia, Z. Modelling ecosystem water supply services across the Lancang River Basin. J. Resour. Ecol. 2011, 2, 322-327.

52. Lin, S.; Wu, R. The spatial pattern of water supply ecosystem service in the Three Parallel Rivers Region. J. West China For. Sci. 2015, 44, 8-15.

53. Canqiang, Z.; Wenhua, L.; Biao, Z.; Moucheng, L. Water yield of Xitiaoxi river basin based on InVEST modeling. J. Resour. Ecol. 2012, 3, 50-54. [CrossRef] 